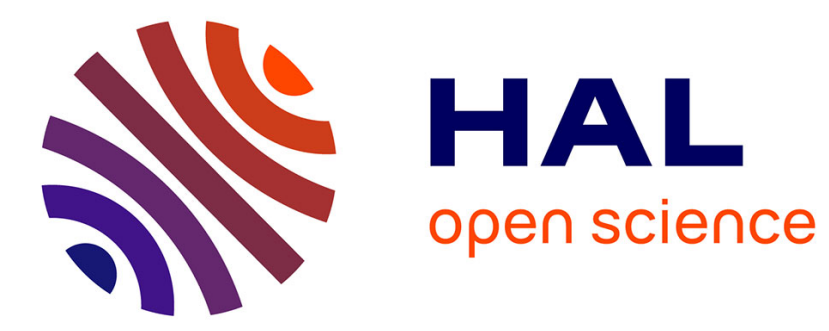

\title{
Stripping at the Bitumen-Aggregate Interface: A Laboratory Method To Assess the Loss of Chemical Adhesion
}

J. Vinet-Cantot, Vincent Gaudefroy, F. Delfosse, Emmanuel Chailleux, E. Crews

\section{To cite this version:}

J. Vinet-Cantot, Vincent Gaudefroy, F. Delfosse, Emmanuel Chailleux, E. Crews. Stripping at the Bitumen-Aggregate Interface: A Laboratory Method To Assess the Loss of Chemical Adhesion. Fizika Nizkih Temperatur, 2019, 33 (4), pp. 2641-2650. 10.1021/acs.energyfuels.8b03410 . hal-03247773

\section{HAL Id: hal-03247773 https://hal.science/hal-03247773}

Submitted on 3 Jun 2021

HAL is a multi-disciplinary open access archive for the deposit and dissemination of scientific research documents, whether they are published or not. The documents may come from teaching and research institutions in France or abroad, or from public or private research centers.
L'archive ouverte pluridisciplinaire HAL, est destinée au dépôt et à la diffusion de documents scientifiques de niveau recherche, publiés ou non, émanant des établissements d'enseignement et de recherche français ou étrangers, des laboratoires publics ou privés. 


\section{Stripping at the bitumen-aggregate interface: A la-}

2 boratory method to assess the loss of chemical adhe-

3 sion

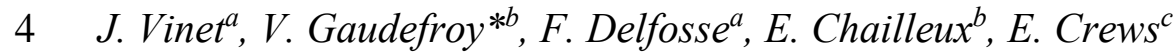

5 a Eurovia Management, Research Center, 22, rue Thierry Sabine, 33703 Merignac Cedex,

6 France

$7 \quad$ b IFSTTAR, Route de Bouaye, CS4, 44344 Bouguenais, France

$8 \quad$ c Ingevity Corporation, 5255 Virginia Avenue, North Charleston, SC 29406, United States of

9 America

$10 *$ Corresponding Author: To whom correspondence should be addressed

11 The manuscript was written through contributions of all authors. All authors have given approval

12 to the final version of the manuscript. They declare no competing financial interest.

13

14 Funding Sources

15 This research was funded by ANRT ( $\left.{ }^{\circ} 2015 / 1091\right)$.

18 Keywords:

19 Bitumen, stripping, kinetic, coated surface, imaging processing. 
2 Moisture damage, cracking, and deformation are the three chief distresses caused by traffic and

3 climate during the service life of an asphalt pavement. One manifestation of moisture damage is

4 the loss of bond between bitumen and aggregate, resulting in the displacement of the bitumen in a

5 process called stripping. While numerous tests try to evaluate moisture damage in the laboratory,

6 most of them show poor correlation with field performance. A fuller understanding of stripping is

$7 \quad$ still needed to enable paving technologists to predict and prevent the effects of moisture damage.

8 This study aims to develop a new stripping resistance evaluation technique wherein adhesion is

9 measured exclusively as a function of the chemical interaction between bitumen and aggregate. A

10 key element of the evaluation technique discussed herein uses a time-lapse image analysis method

11 to characterize the dynamic wetting of precisely applied bitumen droplets on the surfaces of pol-

12 ished mineral aggregates during immersion in a thermo-regulated water bath. At fixed water im-

13 mersion temperatures, the applied bitumen droplets contract, and the image analysis technique

14 allows measurement of the change with time in the surface area of the contracting bitumen droplet.

15 Different bitumen-aggregate pairs were used in this study. This technique allows the bitumen-

16 aggregate pairs to be ranked according to their resistance to moisture damage. This technique also

17 allows calculation of stripping kinetics and loss of the bitumen-aggregate adhesive bond of nine

18 samples in exactly the same conditions. Repeatability of the new method is reported. Lastly, the

19 results of the dynamic stripping analyses are compared to the results from the boiling water test on

20 loose mixture to compare ranking of performances according to the mineralogy. 


\section{INTRODUCTION}

2 Individually or in combination, the mechanical, thermal, and oxidative stresses caused by traffic,

3 climate, respectively and aging may adversely alter the strength and viscoelastic properties of as-

4 phalt pavements, leading to deterioration in overall performance and durability [1]. Kiggundu

5 and Roberts [2] defined moisture damage as 'the progressive functional deterioration of a pave-

6 ment mixture by loss of the adhesive bond between the asphalt cement and the aggregate surface

7 and/or loss of the cohesive resistance within the asphalt cement principally from the action of

8 water.

9 Moisture damage is considered as one of the most important factors in premature deterioration of

10 asphalt pavements and leads to an estimated annual \$54 billion in control and remediation costs

11 in America [3]. Because of that, most of the American transportation agencies specify minimum

12 standards in moisture susceptibility tests. In cases of low performance job mix formulas, $82 \%$ of

13 the agencies recommend the use of antistripping additives to prevent damage caused by moisture

14 damage [4].

15 During mixture production, precise control of both the quality of formulation ingredients (aggre-

16 gates, bitumen, and other materials) and plant operating conditions (e.g., temperature and mixing

17 time) ensures that mineral aggregate surfaces are fully coated by bitumen at the targeted layer

18 thickness. The wetting and coating of aggregate surfaces by bitumen during plant mixing is an

19 example of active adhesion. Likewise, during construction, low air voids are sought, in part, be-

20 cause the interfacial bond between bitumen and aggregate may be susceptible to weakening or

21 full rupture by water that intrudes into the pavement. The breaking of the adhesive bond between 
1 bitumen and aggregate in compacted mixtures is known as stripping and is a form of passive ad-

2 hesion. Thus, the strength and durability of the adhesive bond (passive and active) between bitu-

3 men and an aggregate surface depends on numerous production and construction variables.

4 Traditionally, studies concerning moisture damage have aimed to identify the damage mecha-

5 nism of road pavement materials in the presence of water and to develop or improve the tests for

6 control and prevention in laboratories [5][6]. Indeed, there are numerous standardized laboratory

7 test methods to measure moisture damage in use today [7]. Testing conditions and experimental

8 procedures vary widely from test method to test method (duration of the water immersion cycle

9 and water conditioning temperatures, required specimen air voids, saturation levels, etc). Though

10 large in number and varied in procedural details, today's moisture sensitivity tests for bituminous

11 materials can generally be divided into two broad categories. The first one comprises tests

12 wherein thoroughly coated bituminous mixtures are evaluated for the percent of retained surface

13 coating after immersion of the mixture in water. The percentage of the mineral aggregate surface,

14 which remains coated after water conditioning, may be estimated visually as well as by instru-

15 mental methods like image analysis [8][9]. Examples of these standardized test methods include

16 ASTM D3625 [10] and XP T 66-043-2 [11]. The second category of standardized moisture sen-

17 sitivity tests measures mechanical properties of compacted bituminous mixtures after condition-

18 ing in water and compares the properties of the moisture-conditioned compacted specimens to

19 the same mechanical properties of compacted specimens that have been stored in air or otherwise

20 not exposed to moisture. Such test methods include NF EN 13967-12 [12] and AASHTO T283

21 [13]. All the test methods within each of these two categories share a common purpose: to pro-

22 vide the pavement technologist a predictive measure of the likelihood that a bitumen-aggregate

23 pair is susceptible to the potentially damaging effects of moisture in the field. 
1 However, most of them are limited by their empirical nature, the dependence on the moisture

2 conditioning methodology and mostly their poor predictive power in field performance. If test

3 specimen manufacturing conditions in the laboratory are not representative of field mix produc-

4 tion and pavement construction conditions (for example, with regard to temperature control and

5 heat history), then the predictive utility of the lab test will be limited. Indeed, in one comparative

6 study it was found that the mixture, which was best according to the lab test, was not the best un-

7 der field conditions [14]. Additionally, it has been observed that procedures for water condition-

8 ing of laboratory specimens may not be representative of moisture exposure conditions in the

9 field [15]. A better understanding of the fundamental phenomena at the bitumen/aggregate inter-

10 face during moisture conditioning is needed, as this would enable researchers to understand strip-

11 ping of the bitumen film from the aggregate surface independent of the conditioning procedure.

12 To provide a more comprehensive understanding of stripping phenomena, an approach to evalu-

13 ating moisture susceptibility directly from the properties of the interface between aggregate and

14 bitumen has been developed during the last decade. Many researchers have studied various as-

15 pects of physico chemical characteristics (composition, surface properties) of the mix compo-

16 nents (bitumen and aggregates) and adhesive bond between them [16][17][18]. Measurement of

17 contact angles and calculation of the work of bitumen-aggregate adhesion in the absence of water

18 have been the topics of various research articles [19][20][21]. In the presence of water, bitumen-

19 aggregate bonds break and contact angles increase with time of immersion [22]. Basu shows this

20 phenomenon with bitumen drops on glass slides: the film of bitumen in contact with water be-

21 comes distorted and adopts a spherical shape to minimize interfacial energy [22]. The results of

22 these experimental approaches to measuring stripping are largely influenced by the chemical 
1 composition of bitumen and mineral aggregates. It is well known that the mineralogy of the ag-

2 gregate contributes to the strength and durability of the adhesive bond [1][23]. Indeed, research

3 has shown bitumen interfaces with calcareous aggregate such as limestone generally show

4 greater resistance to the intrusion of moisture than interfaces formed by bitumen and siliceous

5 mineral aggregates.

6 THEORETICAL BASIS

7 Moisture damage is defined as the degradation of the mechanical performance of asphalt mix-

8 tures due to the presence of moisture. The damage phenomenon involves loss of adhesion be-

9 tween bitumen and aggregate. To understand the evolution of the bitumen-aggregate interface, it

10 is important to explain the five different adhesive bond theories.

11 Rice and Thelen described the mechanism of adhesion using a lock and key model [24][25].

12 Their mechanical point of view was predicated on the well-known fact that at elevated tempera-

13 tures, bitumen viscosity is sufficiently low to allow bitumen to thoroughly spread over the asper-

14 ities of mineral aggregates surfaces and penetrate into the aggregate micro-pores. Thus, in this

15 model, the quality and tenacity of the "lock" depends on the viscosity of the bitumen and the tex-

16 ture of the surface [2]. Considering aggregate angularity, interlock adhesion is promoted with

17 high angularity [26].

18 The results of other research have advanced the theory that the bond between bitumen and aggre-

19 gate is influenced by the forces of attraction between different chemical functionality in the bitu-

20 men and on the aggregate surface [16][27][28][29][30]. It is adhesion due to chemical reaction

21 between bitumen and aggregate with the formation of a new material. Considering this theory,

22 the characterization of the active functional groups in bitumen and on the aggregate surface is 
1 essential. In the presence of water, it is important to identify which functional groups in bitumen

2 are displaced by water. Hefer summarized three studies and showed that generally, the most

3 strongly adsorbed functional groups are easily displaced by water, meaning that displacement of

4 bitumen by water is chemically favored [17]. This theory is also useful to understand the action

5 of additives in improving mix moisture resistance.

6 Adhesion also can result from other chemical interactions between aggregate and bitumen, but

7 without formation of new material. Adhesive interactions can be electrostatic in nature, arising

8 from Coulombic forces of attraction [31]. Water damage has been evaluated from the evolution

9 of zeta potential at the aggregate/bitumen interface. Adhesive interactions can also be explained

10 as the result of thermodynamic phenomenon, which depend on the surface free energy of the ma-

11 terials and the work needed to create a new unit surface area. Moisture susceptibility, in this the-

12 ory, can be defined as the change in free energy when water displaces bitumen from the aggre-

13 gate surface.

14 A final theory, which has been enlisted to explain stripping, is the weak boundary theory. Ac-

15 cording to this theory, the adhesive failure may occur due to the existence of an interface region

16 of low cohesive performance [31].

17 The aim of this study is not to advance a new normalized test but to develop a new testing meth-

18 odology for stripping resistance evaluation, wherein different contributions of the various chemi-

19 cal adhesion factors can be isolated. The first part of this paper discusses the characteristics of

20 materials used, the sample preparation procedures, the laboratory experimental conditions, the

21 measurement techniques, and the results obtained with this new methodology, which for simplic-

22 ity is called Method 1. In the latter part of this paper, a comparison is made between the results 
1 of Method 1 and the results of standardized tests for moisture susceptibility in loose materials

2 (Method 2).

4 MATERIALS AND METHODS

\section{$5 \quad 1$ Materials characterization}

\subsection{Surface energy}

7 According to Owens-Wendt theory [32], surface tension or surface energy can be divided into

8 two components, a polar component $\gamma^{P}$, including electron donor and acceptor interactions and a

9 dispersion component $\gamma^{D}$, including Van der Waals interactions. The overall surface energy or

10 surface tension, $\gamma$, according to Owens-Wendt theory is expressed in Equation 1.

$$
\gamma=\gamma^{P}+\gamma^{D}
$$

13 The Fowkes equation (Equation 2) expressing the interfacial tension $\gamma_{S L}$ between and solid and

14 liquid in terms of the components of the surface energy of the solid $\gamma_{S}$ and the surface tension of

15 the liquid $\gamma_{L}$ and Young equation (Equation 3), it is possible to calculate the solid surface energy

16 and its components from contact angles of different reference liquids:

$$
\gamma_{S L}=\gamma_{S}+\gamma_{L}-2 \sqrt{\gamma_{S}^{D} \gamma_{L}^{D}}-2 \sqrt{\gamma_{S}^{P} \gamma_{L}^{P}}
$$

$$
\gamma_{S}=\gamma_{S L}+\gamma_{L} \cos \theta
$$

20 Where $\gamma_{S}^{D}$ and $\gamma_{L}^{D}$ are dispersive components and $\gamma_{S}^{P}$ and $\gamma_{L}^{P}$ are polar components of respec-

21 tively surface tension of the solid $\gamma_{S}$ and the surface tension of the liquid $\gamma_{L}$ [33]. $\gamma_{S L}$ is the inter-

22 facial tension between the solid and the liquid. 
1 By combining Equations 1, 2 and 3, one can calculate polar and dispersive components of a solid

2 from reference liquid with known polar and dispersive components. Table 1 presents the values 3 of $\gamma_{L}^{P}$ and $\gamma_{L}^{D}$ of four common liquids.

Table 1. Surface tension values of reference liquids and polar and dispersive components

\begin{tabular}{cccc}
\hline Reference liquids & $\boldsymbol{\gamma}_{\boldsymbol{L}}(\mathbf{m N} / \mathbf{m})$ & $\boldsymbol{\gamma}_{\boldsymbol{L}}^{\boldsymbol{P}}(\mathbf{m N} / \mathbf{m})$ & $\boldsymbol{\gamma}_{\boldsymbol{L}}^{\boldsymbol{D}}(\mathbf{m N} / \mathbf{m})$ \\
\hline Ethylene glycol & 47.7 & 30.9 & 16.8 \\
Glycerol & 63.4 & 37.0 & 26.4 \\
Water & 72.8 & 21.8 & 51.0 \\
Diiodomethane & 50.8 & 50.8 & 0.0 \\
\hline
\end{tabular}

6 A thermo-regulated drop tensiometer (DSA 100, Krüss $\mathrm{GmbH}$ ) was used to determine the sur-

7 face energy of aggregates at $25^{\circ} \mathrm{C}$. Blocks of mineral aggregate were cored to 40 -mm diameter,

8 cylindrical specimens. These specimens were then cut under water using a diamond saw to ob-

9 tain approximately $10 \mathrm{~mm}$ thick slides. For each aggregate, the 10 - $\mathrm{mm}$ thick slides were ground

10 to a smoothness of $1 / 4 \mu \mathrm{m}$ and cleaned under distilled water, followed by air drying and storage in

11 a dust-free and low-humidity environment into a calcium chloride desiccator. The delay between

12 surface preparation of slides and contact angle measurements was seven days. Indeed, the influ-

13 ence of the delay between polishing and drop deposit has not been evaluated. For the reason of

14 organization, the delay has been fixed at seven days.

15 Equal volumes of each of the four liquids in Table 1 were applied to the highly-polished, 10-mm

16 thick aggregate slides. The volume of the deposited drops was approximatively $1 \mu \mathrm{L}$ for all the

17 reference liquids. Contact angles of four different reference liquids were measured after $1.0 \mathrm{~min}$

18 of stabilization. For each aggregate, at least eight drops of one reference liquid were deposited on 
1 three different slides, followed by contact angle measurements. The average of the repeat con-

2 tact angles measurements was calculated.

3 Results for the difference aggregates of the study are presented in Figure 1. The surface energy of

4 Limestone 2 has not been measured because a block of mineral was not available in the lab.

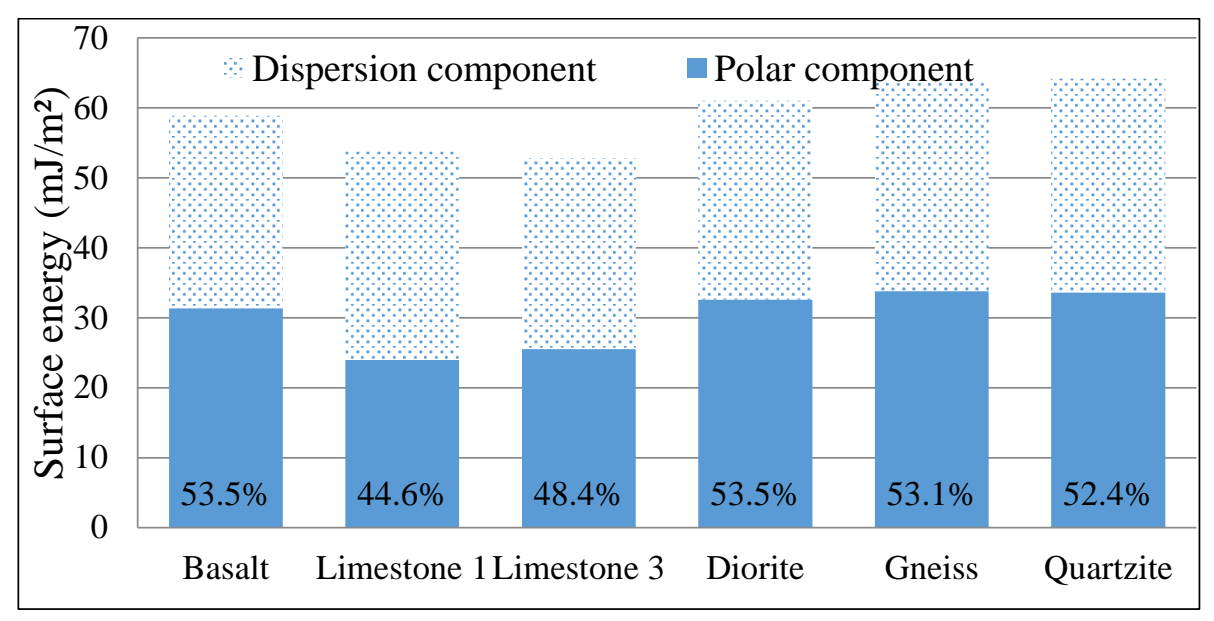

Figure 1. Polar and dispersion components of aggregates and ratio of polarity

\subsection{Mineral characterization}

Chemical composition of the surface of aggregate slides was determined via Micro X-ray Fluo-

rescence. Major components are showed in Table 2. The characterization of Limestone 2 has not

10 been measured because a block of mineral was not available in the lab.

Table 2: Aggregate characterization

\begin{tabular}{|c|c|c|c|c|c|c|}
\hline \multirow[b]{2}{*}{ Aggregates } & \multicolumn{5}{|c|}{ Minerals composition } & \multirow{2}{*}{$\begin{array}{c}\text { Roughness } \\
\text { Sa }\end{array}$} \\
\hline & MgO & $\mathrm{Al}_{2} \mathrm{O}_{3}$ & $\mathrm{SiO}_{2}$ & $\mathrm{~K}_{2} \mathrm{O}$ & $\mathrm{CaO}$ & \\
\hline & $\%$ & $\%$ & $\%$ & $\%$ & $\%$ & $\mu \mathrm{m}$ \\
\hline Basalt & 5.07 & 16.78 & 51.03 & 2.74 & 12.64 & - \\
\hline Limestone 1 & 1.73 & 0.17 & 0.03 & 0.00 & 97.75 & 112 \\
\hline Limestone 2 & - & - & - & - & 98.52 & 147 \\
\hline Limestone 3 & 0.57 & 0.59 & 3.00 & 0.07 & $95.35^{*}$ & 440 \\
\hline Diorite & 0.19 & 11.65 & 68.30 & 10.95 & 3.21 & - \\
\hline Gneiss & 0.00 & 12.50 & 75.40 & 8.89 & 0.83 & - \\
\hline Quartzite & 0.00 & 0.97 & 98.08 & 0.87 & 0.00 & - \\
\hline
\end{tabular}

$11 *$ with microscope observation on aggregates slides, it has been observed carbonated mud in cracks for 12 Limestone 3 


\subsection{Texture characterization}

2 Three different limestones were studied. Roughness evaluation was realized from an optical 3D

3 measurement device from Alicona. The Alicona high-resolution measuring device uses high-res-

4 olution (vertical resolution up to $10 \mathrm{~nm}$ ) photography to create surface profiles. Photographs

5 taken at precisely different altitudes above a surface are superposed to reconstitute surface pro-

6 files and allow measurement of surface roughness $(\mathrm{Sa})$. Because the mineralogy of the three

7 limestone is the same, one can assume that the surface chemistry is the same. Roughness meas-

8 urement has been made only on limestone samples. The arithmetic mean Sa for the limestones is

9 presented in Table 2.

\section{Sample preparation and immersion for Method 2}

12 The boiling water test, ASTM D3625, was conducted in this study. For this test, mixtures were

13 formulated with $6 / 10$ aggregate (i.e., a gradation cut between the $6 \mathrm{~mm}$ and $10 \mathrm{~mm}$ sieve sizes),

14 which had been water washed and dried prior to treatment with a bitumen content of $2.9 \%(250 \mathrm{~g}$

15 of $6 / 10$ sized aggregates and $7.5 \mathrm{~g}$ of bitumen). The retained bitumen coating result was evalu-

16 ated visually after water immersion.

17 Aggregates and bitumen are heated to $150^{\circ} \mathrm{C}$. After adding bitumen to aggregates, the mixture is

18 stirred 1 min while maintaining the temperature at $150^{\circ} \mathrm{C}$. After reducing their temperature to

$1985^{\circ} \mathrm{C}$, coated loose materials are immersed in boiling water for $10 \mathrm{~min}$. After allowing the boiled

20 mixture to cool to room temperature, the retained bitumen coating result is evaluated visually.

21 It is known that stripping phenomenon depends on several parameters, including the physico-

22 chemical properties of the bitumen and aggregate, the manner of mixture manufacturing, and the

23 conditions of moisture exposure. The primary focus of this study, however, is to develop a new 
1 stripping resistance evaluation test. Validation of the method is provided. Then influence of min-

2 eralogy of the aggregate on stripping is studied and results are compared to usual standardized

3 test methods for moisture resistance.

5 EVALUATION OF DROP STRIPPING ON POLISHED AGGREGATE SURFACE - METHOD 1

6 This new method of stripping evaluation studies the dynamic changes in the shape (area) of a bi-

7 tumen drop deposited on a highly-polished aggregate slide while the bitumen-treated slide is im-

8 mersed in water at a fixed temperature. Indeed, in air the final droplet shape is reached when all

9 the forces involved are equilibrated. The contact point between bitumen, air (or water) and ag-

10 gregates is called triple point. When the equilibrium droplet shape is reached, the triple point

11 does not move anymore. When the sample is immersed into water, the interfacial forces may

12 change to reach a new equilibrium in water. This change is the stripping driving force. Forces in

13 both water and air are described in Table 3.

Table 3. Forces active in the system of bitumen and aggregate in air and in water

\begin{tabular}{|c|c|c|}
\hline & In air & In water \\
\hline Surface forces & $\begin{array}{l}\text { Surface tension of bitumen } \\
\text { Adhesion forces between bitumen } \\
\text { and aggregates } \\
\text { Surface energy of aggregate }\end{array}$ & $\begin{array}{l}\text { Interfacial tension between bitu- } \\
\text { men and water } \\
\text { Adhesion forces between bitumen } \\
\text { and aggregates } \\
\text { Interfacial tension between aggre- } \\
\text { gate and water }\end{array}$ \\
\hline Volume forces & $\begin{array}{l}\text { Viscous forces } \\
\text { Gravitational forces }\end{array}$ & $\begin{array}{l}\text { Viscous forces } \\
\text { Gravitational forces } \\
\text { Archimedes force }\end{array}$ \\
\hline
\end{tabular}

14

15

16

17

Difference in forces are due to evolution of surface forces and the addition of Archimedes (or buoyant) force. From the Young equation (Equation 3), the contact angle at the triple point can 
1 be expressed in terms of the surface tensions, $\gamma$, between bitumen, aggregate, and air (or water).

2 Expressions and order of magnitude of different physical quantities are presented in Table 4.

Table 4: Contact angle estimation from the Young equation

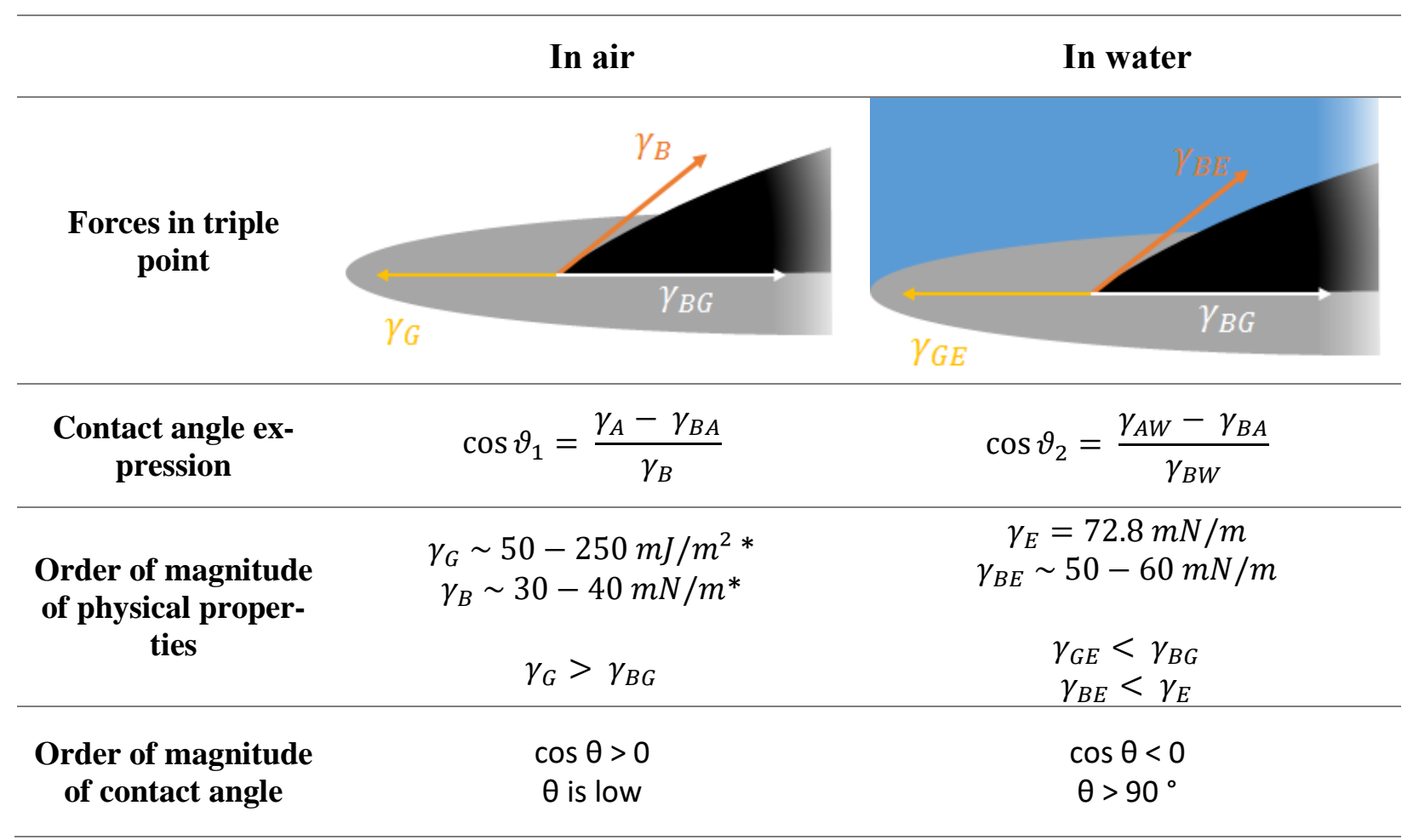

$4 *[1][34][35]$

6 As shown in the schematic representation of forces acting at the triple point in Table 4, $\gamma_{G}$ is the

7 surface energy of aggregate, $\gamma_{B}$ is the surface tension of bitumen, $\gamma_{B G}$ is the interfacial tension

8 between bitumen and aggregate, $\gamma_{G E}$ is the interfacial tension between water and aggregate, $\gamma_{B E}$

9 is the interfacial tension between water and bitumen. The contact angle formed by the bitumen

10 droplet in air, $\Theta_{1}$, is smaller than the contact angle in water, $\Theta_{2}$, These differences in contact an-

11 gles and surface energies of the two systems are responsible for the contraction of the bitumen

12 drop during water immersion. 
1 The experimental method allowed data acquisition on nine drop samples simultaneously. The

2 step-by-step experimental protocol for aggregate polishing, droplet application, water immersion,

3 and photographic treatment of the specimens are described in the following section. Then the

4 analysis of experimental results is described.

51 Experimental protocol

$6 \quad 1.1$ Aggregate polishing

7 Four cleaned and dried aggregates of 6/10 sizes were rendered immobile by partial embedment

8 in a curable liquid resin. For each aggregate, slides with four impregnated aggregates were

9 ground as described in Table 5.

Table 5. Grinding and polishing protocol for thin aggregates slides

\begin{tabular}{|c|c|c|c|c|}
\hline & Disk & Lubricant & $\begin{array}{l}\text { Time } \\
\text { (min) }\end{array}$ & $\begin{array}{c}\text { Rotation speed } \\
\text { (rpm) }\end{array}$ \\
\hline \multirow[t]{3}{*}{ Pre grinding } & MD Piano 220 & Water & 8 & 250 \\
\hline & MD Piano 1200 & Water & 8 & 200 \\
\hline & MD Piano 4000 & Water & 8 & 200 \\
\hline \multirow[t]{3}{*}{ Grinding } & MD Dac & $6 \mu \mathrm{m} *$ & 6 & 150 \\
\hline & MD Dac & $3 \mu \mathrm{m}^{*}$ & 6 & 150 \\
\hline & MA Nat & $1 / 4 \mu \mathrm{m} *$ & 2 & 100 \\
\hline
\end{tabular}

* Aqueous solution of polycrystalline diamond of 6,3 and $1 / 4 \mu \mathrm{m}$ size.

12 Slides are cleaned under distilled water, followed by air drying and storage in a dust-free and

13 low-humidity environment. The delay between polishing and bitumen drop deposit is seven days.

\subsection{Drop deposit}

16 A drop tensiometer (DSA 100, Krüss $\mathrm{GmbH}$ ) was used to deposit bitumen drops. Specimens

17 were positioned on a manual table, which was movable in the $\mathrm{x}, \mathrm{y}$ and $\mathrm{z}$-axes. Solid samples af18 fixed to the manual table were precisely oriented along the desired optical axis. Key features of 
1 the optical instrument included a halogen light source, a frame grabber camera with a $780 \times 580$

2 pixel resolution, and a zoom/focus mode. A glass syringe was used to precisely apply and form

3 the bitumen droplets on the polished aggregate slides.

4 The thermal cell of this tensiometer allows for precise temperature control during testing. Pol-

5 ished aggregates are placed in an oven at the aggregate temperature and are equilibrated for $3 \mathrm{~h}$

6 prior to beginning the experiment. The syringe was also equilibrated at the bitumen deposit tem-

7 perature. Test bitumen samples were added in the 10-mL glass dosing syringe (with a $2.1-\mathrm{mm}$

8 diameter needle) only $15 \mathrm{~min}$ to be sure that there was no aging phenomenon.

9 The syringe was introduced in the dosing cell, and the polished aggregate was placed in the

10 measurement cell. The piston of the syringe was fixed to a micrometric screw to enable precise

11 and accurate control of drop volume. Bitumen temperature $T_{b}$ is chosen so that the bitumen vis-

12 cosity is 0.2 Pa.s, which is a common coating viscosity used in the asphalt paving industry. Ag-

13 gregates temperature $T_{a}$ is chosen at $40^{\circ} \mathrm{C}$ under bitumen temperature, which is not representa-

14 tive of realistic industrial methods. However, this lower aggregate temperature was employed to

15 simulate low adhesion condition during the droplet coating and spreading process; consequently,

16 stripping is favored. One bitumen drop was deposited on each test aggregate. On average, four

17 drops of one bitumen per aggregate slide could be studied simultaneously. After depositing the

18 drop, the samples were covered with a protective bell jar to prevent dust contamination.

19 All contact angles were measured using DSA software (Krüss $\mathrm{GmbH}$ ), following axisymmetric

20 drop shape analysis (ADSA). Two numerical approaches can be used: Tangent-Method 1 and

21 Circle fitting. The first one is based on the mathematical equation of an ellipse, while the second 
1 one consists of the resolution of a higher-order polynomial equation. These are standard numeri-

2 cal analysis procedures for drop shape analysis and permit highly precise drop volume measure3 ment.

\subsection{Sample immersion}

6 One day (24 h) after the bitumen drops were deposited on the polished mineral aggregate sam-

7 ples, the test specimens were pre-heated to the chosen water temperature for $3 \mathrm{~h}$. An image of the

8 drop-aggregate specimens was taken before water immersion. After immersion of the test speci-

9 mens in hot distilled water, photographs were taken every five min for the first hour, then every

$1020 \mathrm{~min}$, and to finish every $90 \mathrm{~min}$ during $20 \mathrm{~h}$. In this studied, the temperature of the water is $1170^{\circ} \mathrm{C}$.

12 Photographs are taken from an overhead vantage point to measure the drop surface instead of

13 taking photographs of the droplet profile, as with contact angle measurement. Indeed, in case of

14 droplets on non-homogeneous and/or rough surfaces, contact angles are not constant and can

15 vary significantly from one profile photograph to the other.

\subsection{Pictures treatment}

18 Photographs taken during water immersion were analyzed using a free, online software, Image J.

19 The software was used to detect all drops on the picture, measure the surface area of each one,

20 and report the results in units of $\mathrm{mm}^{2}$. The photographs were converted from color to gray-scale,

21 employing 255 shades of grey. A filter was applied to establish which grey shades corresponded

22 to bitumen, and which corresponded to the aggregate. The filtered images were then completely 
1 converted to black and white images. Figure 2 shows the evolution of the photographs during the

2 treatment.

3

4
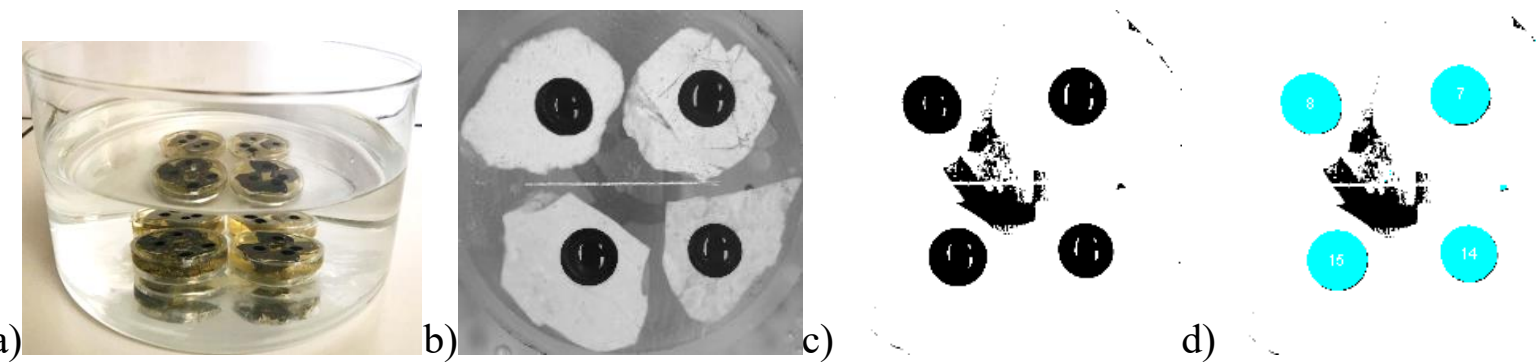

d)

Figure 2. Evolution of the sample photographs a) samples in water; b) 8-bit image; c) black and white image; and d) drop detection

5 From this image analysis using Image $\mathrm{J}$, the initial area (at time, $\mathrm{t}=0$ ) of the bitumen droplet

6 was defined as $S(t=0)$. The area of the bitumen droplet at some time $t$ was defined as $S(t)$. A plot

7 of $\mathrm{S}(\mathrm{t}) / \mathrm{S}(\mathrm{t}=0)$ is shown in Figure 3 for three different polished aggregate specimens (dotted 8 line).

\section{Data analysis}

10 A plot of $\mathrm{S}(\mathrm{t}) / \mathrm{S}(\mathrm{t}=0)$ is shown in Figure 3 for three different polished aggregate specimens. It can

11 be seen in Figure 3 that equilibrium values for $\mathrm{S}(\mathrm{t})$ were reached after around $120 \mathrm{~min}$. From an

12 analysis of results like those shown in Figure 3, Equation 4 is derived as a theoretical description

13 of the dynamic evolution of the relative change in droplet surface area with time of immersion.

$$
\frac{S(t)}{S(t=0)} * 100=A-(A-100) e^{-\frac{t}{\tau}}
$$

15 The term A stands for the equilibrium value of the percent of residual drop surface. The term $\tau$ 16 represents a time constant and the term $\mathrm{t}$ is the immersion time. 
1 Figure 3 shows very good fit between the theoretical equation (Equation 4) and the measured

2 data. Theoretical data are represented by the continuous line in Figure 3; measured data are indi3 vidual points on the graph.

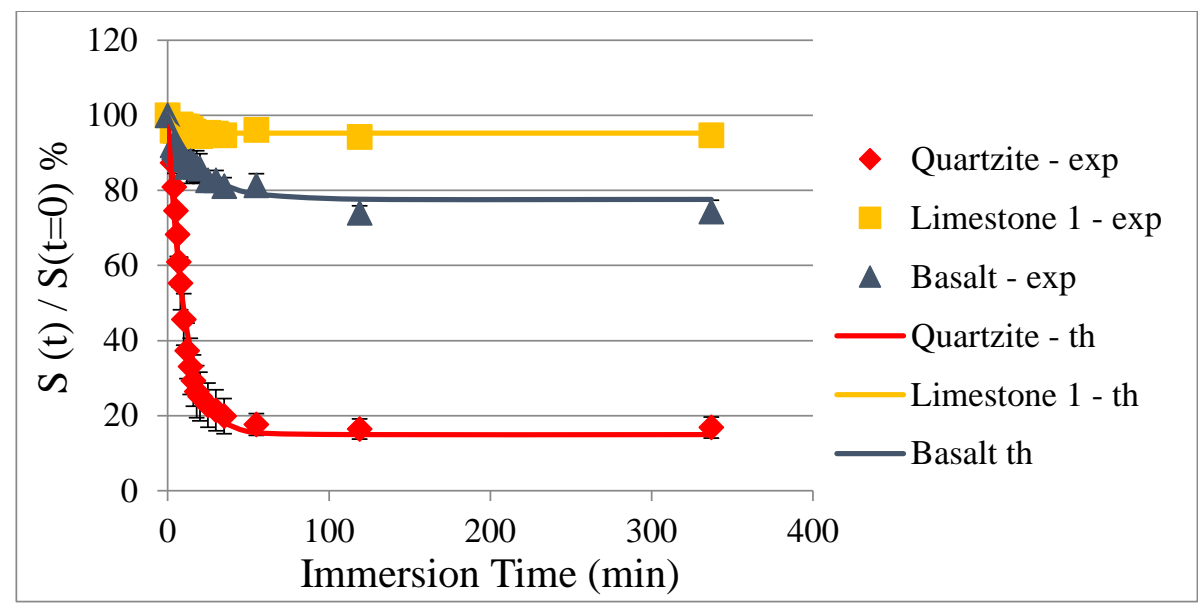

Figure 3. Evolution of the relative surface with immersion time

6 High values of the term A are synonymous with good resistance to the effects of water. The ap-

7 plied bitumen droplet did not contract significantly during water immersion.

8 A dimensional (or unit) analysis in Equation 5 shows that $\tau$ depends on three properties: 1) bitu9 men viscosity $\eta, 2$ ) interfacial tension between bitumen and water $\gamma_{B w}$, and 3) initial bitumen

10 drop surface area $\mathrm{S}(\mathrm{t}=0)$ :

$$
\tau=f\left(\frac{\eta \sqrt{S_{0}}}{\gamma_{B W}}\right)
$$

12 Values for $\mathrm{A}$ and $\tau$ were obtained by the method of least squares. It has been observed that when

13 A is very high, above $90 \%$, error in the value of $\tau$ can be very important. Indeed, the time con-

14 stant describes the behavior of the bitumen/aggregate interface at very short time of immersion.

15 When the drop surface remains constant, there is no single, unique value for $\tau$, which fits well all 
1 the data, but rather a range of values. Consequently, values for the time constant, $\tau$, are not deter-

2 mined if the value of $\mathrm{A}$ is above that $90 \%$.

3 Based on the results with the materials and test parameters used in this study, one can conclude

4 that a high value of $\mathrm{A}$ is a frequent occurrence. To evaluate the influence of this parameter on

5 stripping rates, Equation 6 is used:

6

7

8

$9 v\left(t_{i}\right)$ is the rate of stripping, $S\left(t_{i+1}\right)$ is the drop area at time $t_{i+1}$ and $S\left(t_{i}\right)$ the drop area at time

$10 t_{i}$. The rate of stripping $v\left(t_{i}\right)$ approaches zero because, after a long time of immersion, the

11 equilibrium droplet shape in water is reached, and the triple line (at intersection of bitumen,

12 aggregate and water) does not move anymore. The initial rate of stripping is used to compare

13 bitumen/aggregate.

\section{Validation of Method 1}

15 To evaluate the influence of bitumen drop volume and the repeatability of the test, a homogene-

16 ous substrate is used. Tests are performed on bitumen-glass pairs with the following conditions:

17 Bitumen temperature $T_{b}=150^{\circ} \mathrm{C}$, glass slide temperature $T_{a}=110^{\circ} \mathrm{C}$, water temperature $T_{w}=$ $18 \quad 65^{\circ} \mathrm{C}$.

19 
2 To rank bitumen/aggregates pairs from one to another, speeds are compared for a given contact

3 angle. In this study, drops are considered as partial spheres because the drop radius is inferior to

4 the capillary length, as described in Equation 7:

$$
\kappa^{-1}=\sqrt{\frac{\gamma_{B}}{g \rho_{B}}}
$$

6 With $\gamma_{B}$ the interfacial tension between bitumen and water, $g$ is the gravitational constant and $\rho_{B}$

7 is the bitumen density. In case of bitumen, $\kappa^{-1}$ is approximatively $1.9 \mathrm{~mm}$. Gravitational forces

8 are taken into account when $\kappa^{-1}<<\mathrm{R}$, the radius of the drop.

9 A plot of A value versus bitumen drop volume is shown in Figure 4. Nine drops were studied

10 with volumes ranging from $2.2 \mu \mathrm{L}$ to $29.0 \mu \mathrm{L}$.

11

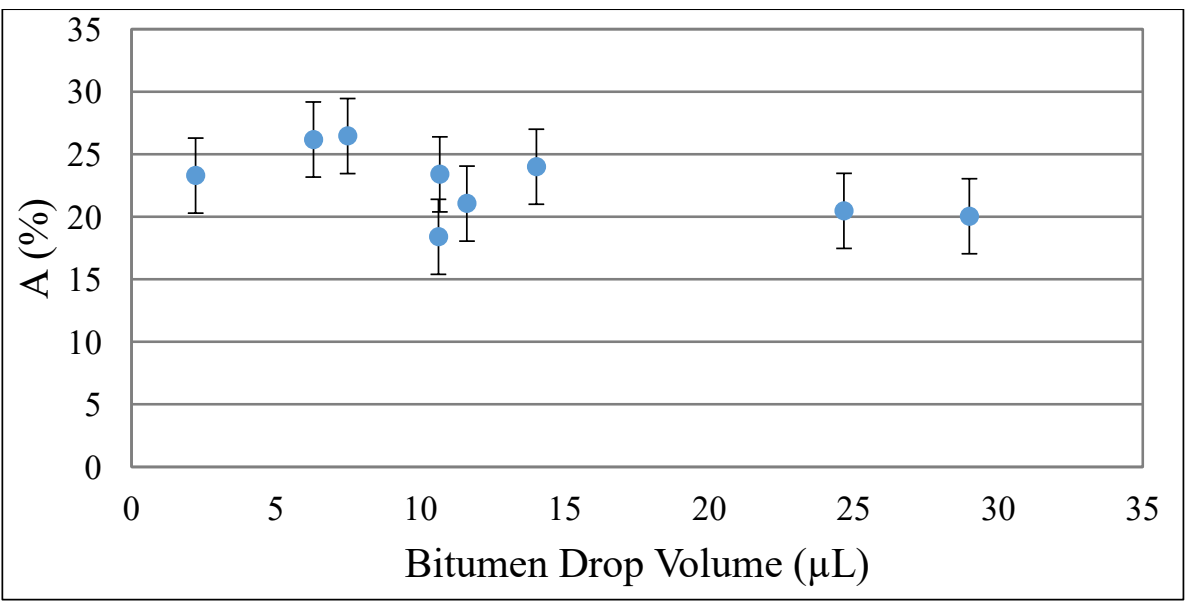

Figure 4. Influence of Bitumen Drop Volume on A Value

14 In the volume range studied, increasing drop volume seems to have a small, downward influence

15 on A value. Indeed, the higher the volume drop, the lower is the A value.

16 A plot of stripping rate versus immersion time is shown in Figure 5. 
4 For drop volumes from 6.3 to $24.7 \mu \mathrm{L}$, initial rate of stripping $v\left(t_{0}\right)$ is in a range between 6.3

5 and $8.9 \mathrm{~mm}^{2} / \mathrm{min}$. For a $2.2 \mu \mathrm{L}$ drop and for a $29.0 \mu \mathrm{L}$ drop, the stripping rates are, respectively,

6 significantly higher and lower for a very short time of immersion.

7 Based on the results in Figure 4, Figure 5 and based on the fact that mineral substrates are more

8 heterogeneous than glass slides, the volume of the bitumen droplets in this study were fixed at 9 $9 \pm 3 \mu \mathrm{L}$.

10

11 Two set of four drops were studied for repeatability of the tests on glass. Preparation techniques

12 and immersion parameters are those described above. All the values for A and $\tau$ are presented in 13 Figure 6.

Figure 5. Evolution of stripping rate vs immersion in water for different drop volumes $(\mu \mathrm{L})$

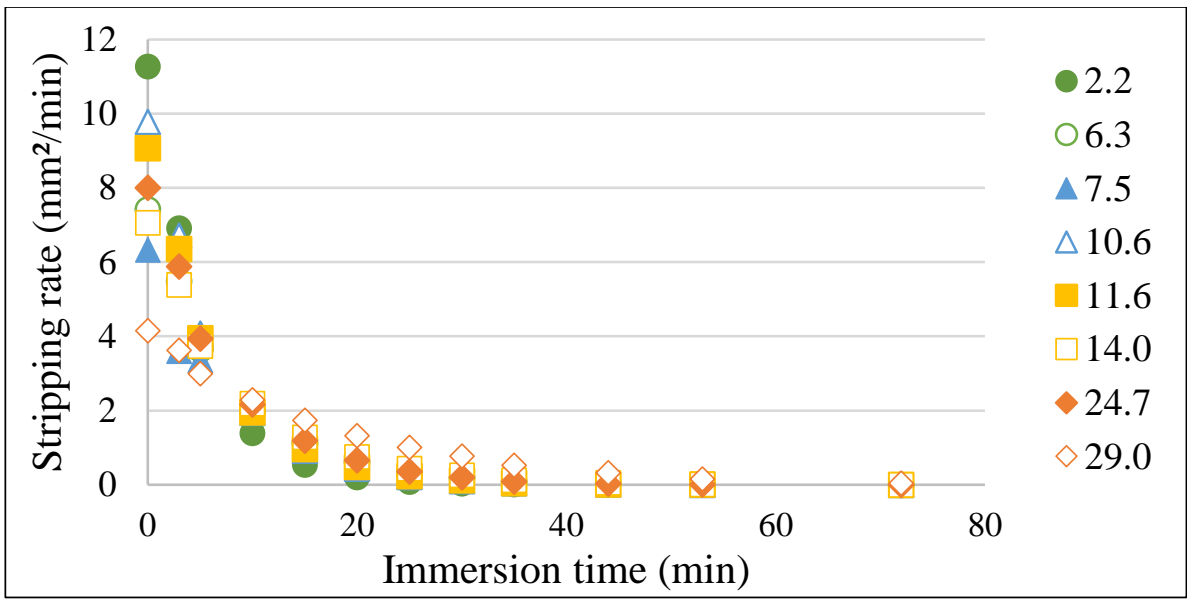




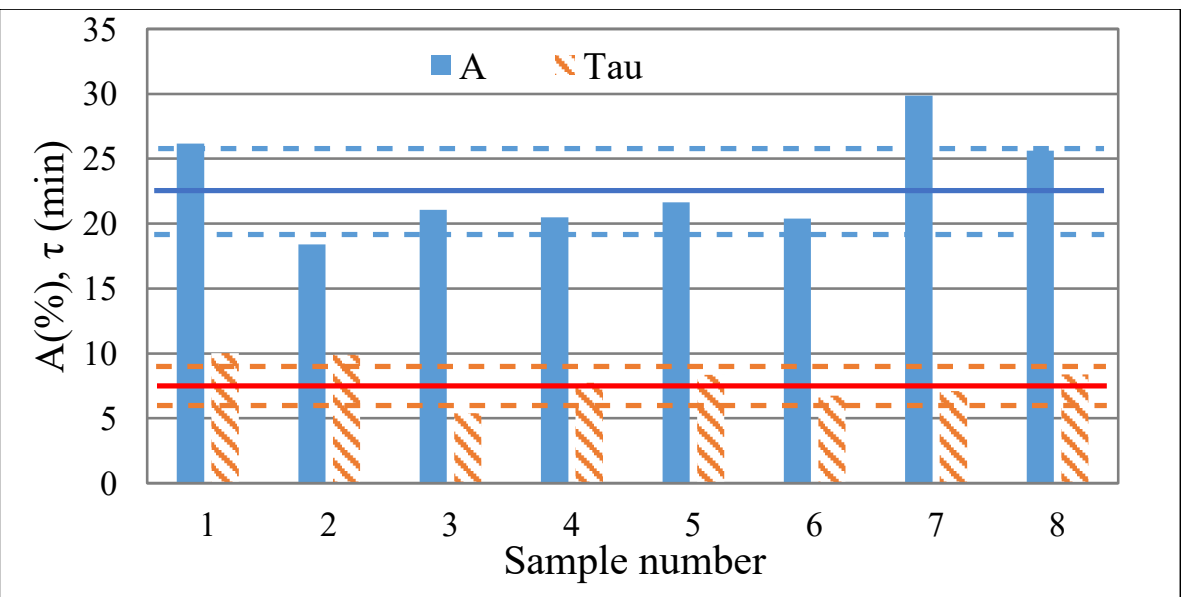

Figure 6. Values for A and $\tau$ for the Eight Tested Specimens

3 The average value for $\mathrm{A}$ is $23.7 \pm 3.4 \%$ (error rate is $14 \%$ ) and for $\tau=7.9 \pm 1.2 \mathrm{~min}$ (error rate is $4 \quad 15 \%)$.

5 A plot of the stripping rates versus immersion time for the eight specimens is shown in Figure 7.

6 The standard deviation is decreasing with immersion time. The rate of stripping at the initial time

7 is $8.3 \pm 1.0 \mathrm{~mm}^{2} / \mathrm{min}$. The error rate is smaller than $15 \%$ which is satisfying. This new method 8 appears suitable to evaluate adhesion forces of different bitumen/aggregate pairs.

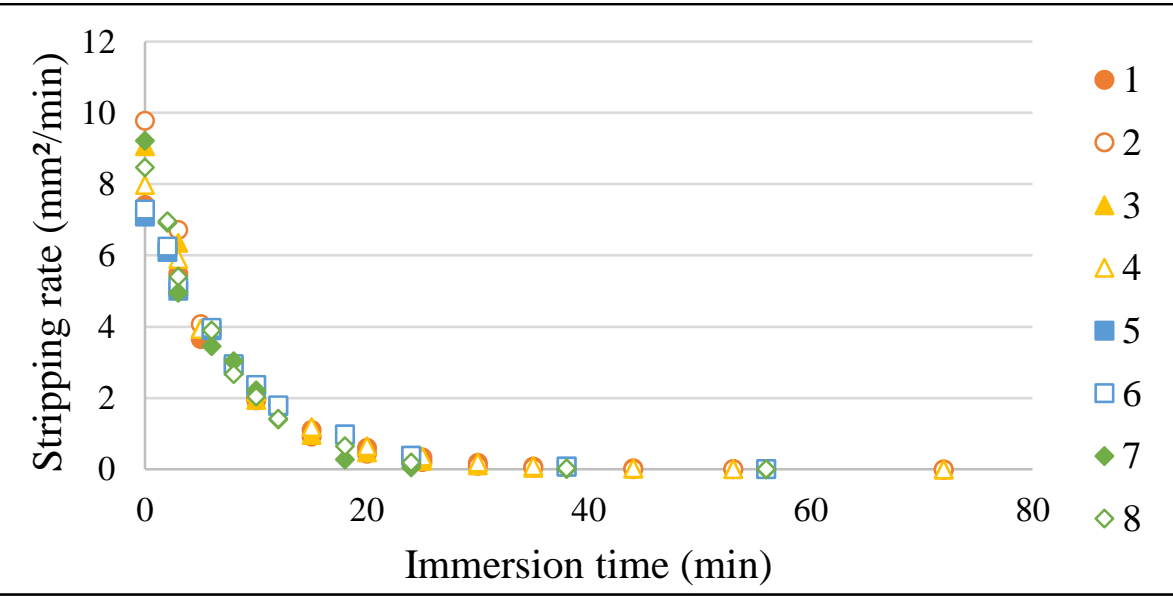

Figure 7. Evolution of Stripping Rate vs Immersion Time for eight specimens studied 
2 The described method allows one to simplify evaluation of the dynamics of a bitumen/substrate

3 interface having a very clean and smooth substrate surface. Good experimental repeatability is

4 obtained because preparation conditions use precise droplet volume application techniques and

5 immersion conditions and measurement techniques are also precisely and accurately controlled.

6 To compare and rank different pairs of bitumen/aggregate surface, two indicators are used:

7 - The A value, which is the area of the retained coated surface, reflects the intensity of strip$8 \quad$ ping phenomenon

$9 \quad-$ And, the time constant and more notably, the rate of stripping, $v\left(t_{i}\right)$, for a given contact 10 angle allows one to evaluate the kinetics of the stripping phenomenon for a given bitu11 men/aggregate pair.

\section{COMPARISON WITH METHOD 2}

\section{Evaluation of coated surface after immersion by binary photographic (image) analysis}

15 Coated aggregates are inserted into rectangle based container, which is situated on a jack. A

16 camera is positioned at $70 \mathrm{~cm}$ from the specimen, and spotlights are directed onto the specimen

17 at a small incident angle to limit light reflection. A photograph is taken of each side of the con18 tainer.

19 As previously mentioned, the software used for the photographic image analysis is ImageJ. Color 20 photographs (Figure 8.a) were converted into black and white ones (Figure 8.b). The "black and 21 white" photographs contained 255 shades of grey. Again, as described above, a filter was applied 
1 to assign certain grey shades as black, corresponding to the bitumen, and certain shades to be

2 white, corresponding to the mineral aggregate.

3

4

7 The influence of mineralogy on stripping resistance was studied via this image analysis using

9 polished aggregate, and 2) on loose mineral aggregate.

11 Standard boiling test adhesion was used to evaluate the susceptibility of the bitumen-aggregate

12 bond to stripping [10]. Specimens were immersed $10 \mathrm{~min}$ in boiling water. The results are re-

13 ported as the percentage of aggregate surface coated with bitumen after test and after the loose,

14 boiled mixture had been allowed to stand for $10 \mathrm{~h}$ at room temperature. This retained coated sur-

15 face is obtained with the photographic treatment previously described. The results are presented 16 in Table 6.

Figure 8. a) Original Picture; b) Binary Picture for Coated Surface 
1 Quartzite displayed the lowest percent of retained coated surface after immersion with $24.2 \%$ of

2 aggregate having a residual bitumen coating after boiling. In contrast, Limestone 2 displayed the

3 highest percentage of retained aggregate surface coating, with $74.8 \%$ after boiling.

Table 6. Results of boiling test on loose materials

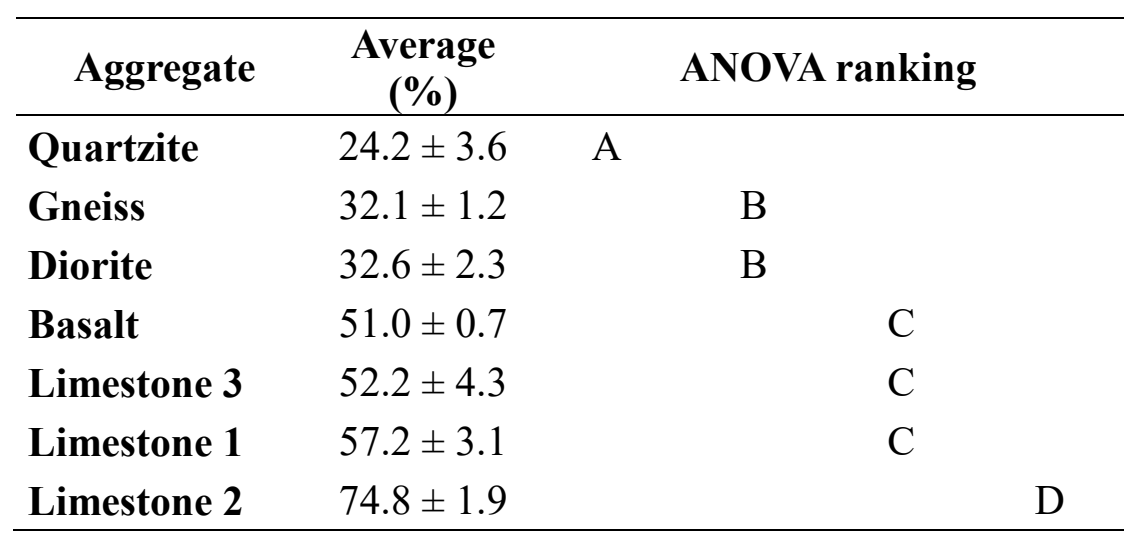

5 The higher the percent of residual coated surface after $10 \mathrm{~min}$ in boiling water in the static immersion condition, the better the resistance of the bitumen-aggregate pair to stripping. Gneiss

7 and Diorite are not significantly different. Moreover Basalt has the same behavior of Limestone

83 and 1. These results are in accordance with research results from other scientists [8][23].

9 Acidic aggregates with high silica content show low resistance to water intrusion. Indeed, car-

10 boxylic acids of bitumen are strongly adsorbed on surface due to hydroxyl group but easily dis-

11 placed by water [16].

$$
\begin{gathered}
--\mathrm{SiOH}+\mathrm{RCOOH} \leftrightarrow--\mathrm{SiOH} \ldots \mathrm{HOOCR} \leftrightarrow--\mathrm{SiOH}_{2}+-\mathrm{OOCR} \\
--\mathrm{SiOH} \ldots \mathrm{HOOCR}+2 \mathrm{H}_{2} \mathrm{O} \leftrightarrow--\mathrm{SiOH} \ldots \mathrm{HOH}+\mathrm{H}_{2} \mathrm{O}+\mathrm{RCOOH}
\end{gathered}
$$

On the contrary, basic aggregates with high carbonate content react with carboxylic acids to form a water-insoluble calcium carbonate salt. 
3 With this test, it was possible to discriminate between the three limestone samples studied. In-

4 deed Limestone 2 is significantly different from the others. Regarding the roughness measure-

5 ments, there is no significant difference in Sa values between Limestone 1 and Limestone 2. The

6 Sa value is more important for Limestone 3. One might hypothesize that during conditioning in a

7 boiling water test, higher roughness makes the bitumen/aggregate interface more susceptible to

8 water intrusion. For example, during mix preparation, micro-pockets of air might be trapped be-

9 tween the bitumen film and the asperities of a rough aggregate surface. A weak bond at those

10 points would facilitate intrusion of moisture.

\subsection{Results using Method 1}

13 Contrary to the previous method where the roughness and macro texture of the aggregate in the

14 static immersion test is a potential variable in stripping resistance, Method 1 used polished ag15 gregate.

16 The change in bitumen drop area (on a polished aggregate surface) was measured as a function

17 of immersion time in heated distilled water as a means of characterize passive stripping. Table 7

18 shows the equilibrium retained surface area A for one bitumen on the seven different polished

19 aggregate surfaces after immersion in water at $70^{\circ} \mathrm{C}$ and the value of the constant time for acid

20 (quartzite and gneiss) and heterogeneous aggregate (diorite and basalt).

21 The lowest A value at $70^{\circ} \mathrm{C}$ was measured with quartzite and gneiss (under $20 \%$ ), whereas all the

22 different limestone showed a high percent of residual surface (more than 90\%). Diorite and bas- 
1 alt aggregate showed intermediate behavior, with respectively $50.8 \%$ and $77.6 \%$. As noted previ-

2 ously, a high percentage of retained droplet surface area (a high A value) indicates good re-

3 sistance to water. The bitumen drop boundary did not recede for the three limestone systems, or

4 in other words, the triple line did not move in the presence of water. The bitumen-limestone in-

5 terfacial bond is more resistant to water intrusion than the bond formed between bitumen and

6 quartzite or bitumen and gneiss.

Table 7. Results of drop stripping after $15 \mathrm{~h}$ of static immersion in water at $70^{\circ} \mathrm{C}$

\begin{tabular}{|c|c|c|c|c|c|c|}
\hline Aggregate & $\mathrm{A}(\%)$ & ANOVA rankin & & $\begin{array}{l}\text { Final contact } \\
\text { angle in water } \\
\left({ }^{\circ}\right)\end{array}$ & Tau (min) & $\begin{array}{c}\mathbf{V}_{(\mathrm{t}=\mathbf{0})} \\
\left(\mathrm{mm}^{2} / \mathbf{m i n}\right)\end{array}$ \\
\hline Quartzite & 14.9 & A & & 132.5 & 10.6 & 6.9 \\
\hline Gneiss & 16.9 & A & & 126.9 & 14.9 & 5.0 \\
\hline Diorite & 50.8 & B & & 64.4 & 83.2 & 0.6 \\
\hline Basalt & 77.6 & $\mathrm{C}$ & & 49.5 & 20.0 & 1.4 \\
\hline Limestone 3 & 93.0 & D & & 38.8 & - & 1.0 \\
\hline Limestone 1 & 94.7 & $\mathrm{D}$ & $\mathrm{E}$ & 41.5 & - & 0.8 \\
\hline Limestone 2 & 95.3 & & $\mathrm{E}$ & 44.4 & - & 0.3 \\
\hline
\end{tabular}

9 The final contact angle at the triple point in water was measured from the drop profile. Values

10 for these final contact angles are presented in Table 7. The higher the contact angle, the more the

11 bitumen droplet receded (or stripped) during water immersion. With quartzite and gneiss, the

12 contact angle exceeded $100^{\circ}$, meaning that interface of the aggregate with water increased at the

13 expense of bitumen-aggregate interfacial area. In contrast, the contact angle on limestone was

14 around $40^{\circ}$, meaning a higher affinity of the bitumen for the limestone than for the water. 
1 The constant time was calculated for all the aggregate except the limestone because $\mathrm{A}$ is higher

2 than $90 \%$ (see Paragraph 2. Data analysis). According to the initial stripping rate, one can con-

3 clude, the lower tau value, the faster is the rate of bitumen withdrawal. Thus, stripping is signifi-

4 cant and rapid for quartzite and gneiss, whereas it is very slow for diorite.

5 From all the measured values, it is possible to classify the bitumen-aggregate pairs according to

6 their stripping resistance. Quartzite and gneiss showed the same behavior. Diorite and Basalt are

7 significantly different. Limestone 3 and Limestone 2 are considered as different even if the re-

8 sults are very close. Limestone 1 is not significantly different from the other limestones.

\subsection{Comparison between Method 1 and Method 2}

11 Differences between the drop test on polished aggregate and the boiling water test include the

12 following. Aggregate in the boiling test are not polished. The Method 1 was conducted at $70^{\circ} \mathrm{C}$

13 whereas the Method 2 was conducted at boiling temperature. Despite these differences, there was

14 a common trend in overall ranking of stripping resistance. Figure 9 shows this commonality.

15 Generally both methods gave results, which indicated that stripping was more significant the

16 higher the silica content of the mineral aggregate.

17 It is worth pointing out also that the values for the percent retained coating in the drop test

18 (Method 1) are lower than those values obtained in the static immersion test (Method 2) for acid

19 aggregates (Quartzite and gneiss) due to aggregate smoothness differences and due to the lack of

20 mechanical action in the Method 1 drop test. 


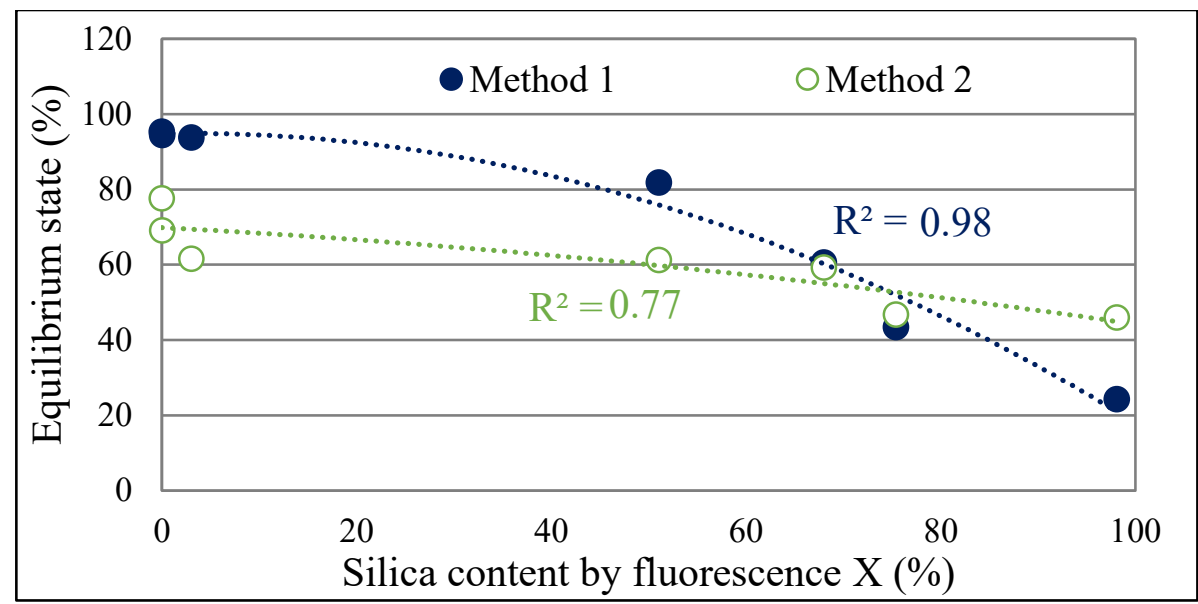

Figure 9. Correlation of Residual Coated Surface with Silica Content

3 One can surmise that with Method 1, adhesion is the result of chemical adhesion, because aggre-

4 gate surfaces are polished to minimize the surface roughness and texture. Indeed, Alicona char-

5 acterization has been realized on polished surface and Sa is very low (from 13 to $27 \mu \mathrm{m}$ ) com-

6 pared to the value for unpolished aggregate presented in Table 2. Polishing contributed to the

7 fact that the value of the coefficient of determination, $\mathrm{R}^{2}$, in Figure 9 is higher for Method 1 than 8 for Method 2.

9 In contrast, while Method 1 cannot discriminate between the three limestones $(\mathrm{A}=94.4 \% \pm$

10 1.3), Method 2 allows one to consider Limestone 2 as better mineral aggregate in terms of mois-

11 ture resistance. Because the mineralogy of the three limestones is the same, one can assume that

12 the surface chemistry is the same, and therefore, Method 1 allows one to measure chemical adhe-

13 sion without taking into account aggregate micro-texture. The aggregates in this study have been

14 chosen because their mineralogy are significantly different. The selected aggregate are repre-

15 sentative of those found in Western Europe. 
2 Water damage and stripping resistance are influenced by numerous parameters. The aim of this

3 work was to develop a new stripping resistance evaluation method which can isolate chemical

4 adhesion from mechanical adhesion.

5 This study introduced a new small-scale test method for moisture sensitivity. The method uses

6 optical image analysis to quantify the strength of bitumen film adhesion to polished aggregate

7 exposed to water at varying temperatures. A precise volume (around $9 \mu \mathrm{L}$ ) of test bitumen is de-

8 posited as a drop on a polished aggregate surface. The area of droplet is measured using optical

9 image analysis. The optically-determined area of the droplet was then measured as a function of

10 time of immersion in water at a range of temperatures. The ratio of the droplet surface area after

11 the immersed sample reached equilibrium (expressed as $S(t)$ ) to the initial surface area of the

12 droplet $(\mathrm{S}(\mathrm{t}=0))$ was a reliable measurement of the resistance of the bitumen film to moisture-

13 induced stripping.

14 Moreover, by carefully characterizing the petrographic characteristics of the polished aggregate

15 surface, the retained surface area ratio $(\mathrm{S}(\mathrm{t}) / \mathrm{S}(\mathrm{t}=0))$ could be correlated with physicochemical

16 properties of the bitumen and aggregate interfaces, such as silica content. Results highlighted dif-

17 ferent families of mineralogy. For example, it was shown that basic aggregates such as lime-

18 stone showed a good resistance to water whereas acid ones, with high silica content, were very

19 susceptible to water. Comparing the result with those of Boiling Test, the impact of roughness is

20 reduced and the kinetic can be evaluated.

21 The impact of bitumen rheological properties is not presented in this paper. However, it is rea-

22 sonable that bitumen rheology, at the temperature of water during the immersion, might have an 
1 impact on A value, the time constant value, $\tau$, and the rate of stripping. The higher the water tem-

2 perature, the lower is the A value and the faster the rate of stripping.

3 The results of the new test method allow researchers to identify bitumen/aggregate pairs resistant

4 to water. Further, the technique discussed herein is a promising tool for the evaluation aggre-

5 gate/additive compatibility. In case of good compatibility between additives and aggregates, A

6 value increase and stripping kinetic reduce. A limit of $90 \%$ on A value has been decided to con-

7 sider additives as useful.

8 In future work, the practical utility of this method (Method 1) will be demonstrated further by

9 comparison with results of other standard moisture resistance test for compacted bituminous

10 mixtures.

\section{ACKNOWLEDGMENT}

13 The authors acknowledge Vincent Rellier for valuable discussions on mineral characterization

14 and Cedric Petiteau, Olivier Burban and Marie Laure Pierre for their experimental contribution

15 to this study.

16

17 REFERENCES

18 [1] Lesueur, D. and Ramond, G., Adhésion Liant Granulats, Matériaux routiers bitumineux,

19 Tome 1, Editions Lavoisier, 2004. 
1 [2] Kiggundu, B.M. and Roberts, F.L., Stripping in HMA mixtures: state-of-the-art and critical

2 review of test methods, Alabama: Auburn University. Report 88-02, National Center for Asphalt

3 Technology, 1988.

4 [3] Copeland, A. Moisture in asphalt pavements in the United States: a financial perspective. In 5 1st Int. Workshop on Moisture Damage, Delft, The Netherlands, 2005.

6 [4] Hicks, G., Santucci, L. and Aschenbrener, T., Introduction and seminar objectives. In Mois7 ture Sensitivity of Asphalt Pavements: a National Seminar, Transportation Research Board, San 8 Diego, California, Washington DC, 2003.

9 [5] Lottman, R.P., Predicting moisture-induced damage to asphaltic concrete: field evaluation, 10 National Academies Press. National Cooperative Highway Research Program, Washington DC, $11 \quad 246,1982$.

12 [6] Aschenbrener, T., McGennis, R.B. and Terrel, R.L., Comparison of several moisture suscep13 tibility tests to pavements of known field performance. J. Assoc. Asphalt Paving Technologists, 14 1995, 64, 163-208.

15 [7] Airey, G.D. and Choi, Y-K., State of the art report on moisture sensitivity test methods for 16 bituminous pavement materials, Road Mater. Pavement, 2002, 3(4), 355-372.

17 [8] Amelian, S., Abtahu, S. M. and Hejazi, S.M., Moisture susceptibility evaluation of asphalt 18 mixes based on image analysis, Constr. Build. Mater., 2014, 63, 294-302.

19 [9] Hamzah, M.O., Kakar, M.R., Quadri, S.A. and Valentin, J., Quantification of moisture sensi20 tivity of warm mix asphalt using image analysis technique, J. Cleaner Prod., 2014, 68, 200-208. 
1 [10] ASTM D36 25, Standard Practice for Effect of Water on Bituminous-Coated Aggregate Us-

2 ing Boiling Water, 2005.

3 [11] XP T 66-043, Liants hydrocarbonés - Essai d'adhésivité - passive des liants anhydres en

4 présence d'eau, Paris, AFNOR, 2006.

5 [12] NF EN 12697-12, Bituminous mixtures. Test methods for hot mix asphalt, Part 12: Determi6 nation of the water sensitivity of bituminous specimens (Method A: ITSR and Method B: Essai

7 Duriez), 2008.

8 [13] AASHTO T283, Resistance of Compacted Bituminous Mixture to Moisture-Induced Dam9 age, 2007.

10 [14] Schram S., Ranking of HMA Moisture Sensitivity Tests in Iowa, SP\&R Project RB10-012,

11 Final Report, Iowa Department of Transportation, 2012.

12 [15] Hicks, R.G., and Epps, J.A. Quality Control for Asphalt-Rubber Binders and Mixes, Rubber 13 Pav. Assoc., Tempe, Arizona, 2000.

14 [16] Little, D.N. and Jones, D., Chemical and mechanical mechanisms of moisture damage in hot 15 mix asphalts pavements. In Moisture Sensitivity of Asphalt Pavements: a National Seminar,

16 Transportation Research Board, San Diego, California, Washington DC, 2003.

17 [17] Hefer, A.W., Little, D.N. and Lytton, R.L., A synthesis of theories and mechanisms of bitu18 men-aggregate adhesion including recent advances in quantifying the effects of water. J. Assoc. 19 Asphalt Paving Technologists, 2005, 74, 139-196. 
1 [18] Bhasin, A., Chowdhury, A., Button, J. and Little, D.N., Evaluation of material property tests

2 to predict moisture susceptibility of HMA, In 10th Int. Conf. Asphalt Pavements (ISAP), Quebec,

3 Canada, 2006, 701-710.

4 [19] Delfosse, F., Maze, M. and Layerle, E., Impact de la température d'enrobage sur l'adhésion

5 bitume/granulat, $R G R A, \mathbf{2 0 1 2}, 902,46-53$.

6 [20] Boulangé, L. and Sterczynski, F., Study of interfacial interactions between bitumen and var-

7 ious aggregates used in road construction, J. Adhes. Sci. Technol., 2012, 26, 163-173.

8 [21] Ziyani L., Gaudefroy V., Ferber V. and Hammoum F., A predictive and experimental

9 method to assess bitumen emulsion wetting on mineral substrates, Colloids Surf. A: Physico-

10 chem. Eng. Aspects, 2016, 489, 322-335.

11 [22] Basu, S., Nandakumar, K. and Masliyah, J. H., Effect of NaCl and MIBC/kerosene on bitu-

12 men displacement by water on a glass surface, Colloids Surf. A: Physicochem. Eng. Aspects,

$13 \mathbf{1 9 9 8 , 1 3 6 , 7 1 - 8 0 .}$

14 [23] Grönniger, J., Wistuba, M. P., Renken, P., Adhesion in bitumen-aggregate systems, New

15 technique for automated interpretation of rolling bottle tests, Road Mater. Pavement, 2010,

$16 \quad 11(4), 881-898$.

17 [24] Rice, J.M., Relationship of Aggregate Characteristics to the Effect of Water on Bituminous

18 Paving Mixtures, Symp. on Effect of Water on Bituminous Paving Mixtures, ASTM STP, 1958,

$19 \quad 240,17-34$. 
1 [25] Thelen, E., Surface Energy and Adhesion Properties in Asphalt-Aggregate Systems, High-

2 way Research Board Bulletin 192, Highway Research Board, 63, 1958.

3 [26] Stuart, K.D., Moisture damage in highway mixtures - a state-of-the-art report, FHWA-RA-

4 90-019, Washington, DC: Department of Transportation., 1990.

5 [27] Plancher, H., Dorrence, S.M. and Petersen, J.C., Identification of chemical types in asphalts

6 strongly absorbed at the asphalt-aggregate interface and their relative displacement by water. $J$.

7 Assoc. Asphalt Paving Technologists, 1977, 46, 151-175.

8 [28] Petersen, J.C., Plancher, H., Ensley, E.K., Venable, R.L. and Miyake, G., Chemistry of as-

9 phalt aggregate interaction: relationship with pavement moisture-damage prediction test, Trans-

10 portation Res. Rec.: J. Transportation Res. Board, 1982, 843, 95-104.

11 [29] Curtis, C.W., Ensley, K. and Epps, J., Fundamental properties of asphalt-aggregate interac-

12 tions including adhesion and adsorption, Strategic Highway Research Program Project SHRP-A-

13 341, Washington, DC: The National Academies Press., 1993.

14 [30] Letoffé, J.M., Claudy, P., Planche, J.P., Germanaud, L., Caractérisation de l'interaction bi-

15 tume-agrégat par microcalorimétrie isotherme, Thermochimica Acta, 1992, 210, 27-40.

16 [31] Allan, K.W., Mechanical theory of adhesion, In Handbook of adhesion, Packham, D.E. Lon-

17 don: Longman Group, UK Ltd, 1992, 273-275.

18 [32] Owens, D.K., Wendt, R.C., Estimation of the surface free energy of polymers, J. Appl. Poly19 mer Sci., 1969, 13 (8), pp. 1741-1747. 
1 [33] Fowkes, F., Dispersion force contributions to surface and interfaciales tensions, contact an-

2 gles, and heats of immersion, Contact angles, wettability and adhesion, Adv. Chem. Series, ACS

3 Washington, 1964, 43, pp. 99.

4 [34] Grenfell, J., Assessing Asphalt Mixture Moisture Susceptibility Through Intrinsic Adhesion,

5 Bitumen Stripping and Mechanical Damage, Road Mater. Pavement, 2014, 15:1, pp. 131-152, 62014.

7 [35] Jolicoeur, C., Etude du mécanisme d'adhésion entre un liant bitumineux et un granulat, 8 Thèse de doctorat, Université de Sherbrooke, 2006. 